\title{
AN EXPERIMENTAL STUDY ON MECHANICAL PROPERTIES OF ALKALI ACTIVATED SLAG CONCRETE
}

Veeresh Karikatti

Research Scholar, Department of Civil Engineering,

B V Bhoomaraddi College of Engineering \& Technology, Hubli, Karnataka, India

\section{Dr. Manojkumar Chitawadagi}

Professor, Department of Civil Engineering,

B V Bhoomaraddi College of Engineering \& Technology, Hubli, Karnataka, India

\section{Dr. Naveen G.M}

HOD, Department of Civil Engineering, Government Engineering College, Chamarajanagara, India

\begin{abstract}
Alkaline activator technology is the key determinant factor in alkali activated slag concrete. Ground Granulated Blast Furnace Slag (GGBS) is one which holds outstanding distinctive properties such as workability, strength, reduction in cost and time and substantial effective in construction. The present work deals with two major aspects one is effect of fibers on fresh and hardened properties of alkali activated slag concrete. The alkali activated slag concrete mixes of $M 1$ indicating $2 M, M 2$ is of $4 M$ and $M 3$ is of $6 M$ were prepared with incorporating fibres by varying percentage of $0 \%$ to $1.5 \%$ by weight of cement at the interval of $0.5 \%$ and the binder ratio of sodium silicate to sodium hydroxide alkaline liquid is $0.4,0.5$ and 0.6 . The result obtained from this work revealed that workability tends to decrease with increase in molarity and for M2 mix the slump obtained was 45-50mm. The compressive strength and split tensile strength were increased for M3 mix with binder ratio of 0.5 and $1 \%$ fibre content and the flexural strength is increased for M3 mix with binder ratio of 0.4 and $1 \%$ fibre content.
\end{abstract}

Keywords: Alkaline Activator Slag, Fiber reinforce, Flexural loading

Cite this Article: Veeresh Karikatti, Manojkumar Chitawadagi and Naveen G.M, An Experimental Study on Mechanical Properties of Alkali Activated Slag Concrete, International Journal of Civil Engineering and Technology (IJCIET), 12(4), 2021, pp. 21-29.

https://iaeme.com/Home/issue/IJCIET?Volume=12\&Issue=4 


\section{INTRODUCTION}

Concrete beam made with AAS cement sets more slowly than concrete beam made with ordinary Portland cement, depending on the amount of AASC in the cementitious material, but also continues to gain strength over a longer period in production conditions [1\&9]. This results in lower heat of hydration and lower temperature rises, and makes avoiding cold joints easier, but may also affect construction schedules where quick setting is required. AASC is used to make durable concrete structures in combination with ordinary Portland or other pozzolanic materials [4]. AAS has been widely used in Europe, and increasingly in the United States and in Asia for its superiority in concrete durability, extending the lifespan of buildings from fifty years to a hundred years [6]. The alkali and silicates content also plays a significant role in the development of compressive strength. The curing condition had a significant effect on mechanical behavior of hardened state of alkaline activated slag paste [2,3 $\& 5]$. The workability of concrete with alkaline activators such as sodium and deals with compressive and Flexural strength of concrete using AAS concrete and fibers [7,8 \&10].

\section{MATERIALS AND EXPERIMENTAL METHODOLOGY}

\subsection{Materials}

The chemical and physical properties of constituents of AASC mixes are shown in Table 1 to 4. The table 5 shows the physical properties of hooked end steel fibres. Ground granulated blast furnace slag (GGBS) shown in Fig.1, alkaline activators $\left(\mathrm{NaOH}+\mathrm{Na}_{2} \mathrm{SiO}_{3}\right)$ shown in Fig.2, fine aggregates, coarse aggregates shown in Fig.3, and water are used for casting the specimens.
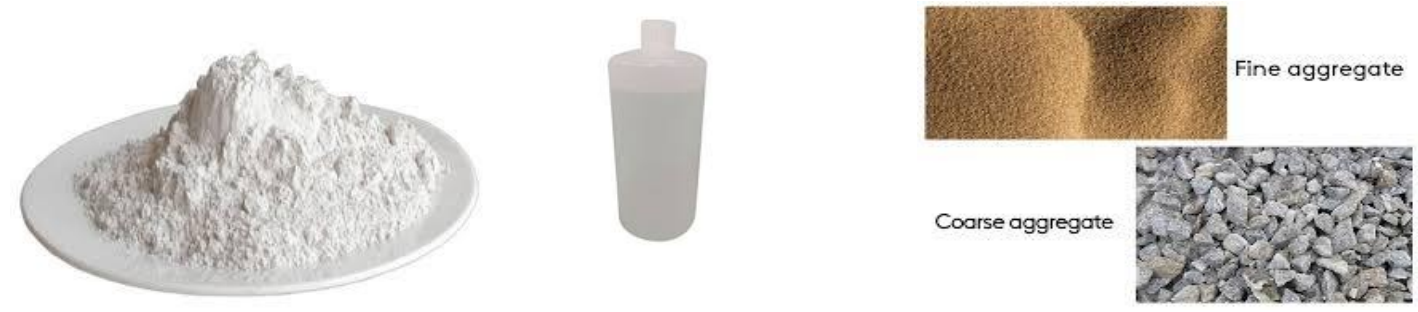

Figure.1: GGBS

Figure.2: Alkaline Solution $\left(\mathrm{NaOH}+\mathrm{Na}_{2} \mathrm{SiO}_{3}\right)$ Figure.3: Fine and Coarse Aggregate

Table 1: Physical properties of GGBS

\begin{tabular}{|c|c|}
\hline Colour & Off-white \\
\hline Specific gravity & 2.84 \\
\hline Bulk density & $1240 \mathrm{~kg} / \mathrm{m}^{3}$ \\
\hline Fineness & $340 \mathrm{~m}^{2} / \mathrm{kg}$ \\
\hline
\end{tabular}

\begin{tabular}{|c|c|} 
Table 2: Chemical Properties of GGBS \\
\hline Compound & \% weight \\
\hline $\mathrm{CaO}$ & 37.34 \\
\hline $\mathrm{Al}_{2} \mathrm{O}_{3}$ & 14.42 \\
\hline $\mathrm{Fe}_{2} \mathrm{O}_{3}$ & 1.11 \\
\hline $\mathrm{SiO}_{2}$ & 37.73 \\
\hline $\mathrm{MgO}$ & 8.71 \\
\hline $\mathrm{MnO}$ & 0.02 \\
\hline Sulphide Sulphur & 0.39 \\
\hline Loss on Ignition & 1.41 \\
\hline Insoluble Residue & 1.59 \\
\hline Glass Content & 92.00 \\
\hline
\end{tabular}


Table 3 : Physical Properties of Fine aggregates

\begin{tabular}{|c|c|c|}
\hline 1. & Maximum size $(\mathrm{mm})$ & 4.75 \\
\hline 2. & Specific gravity & 2.64 \\
\hline 3. & Water absorption (\%) & 0.4 \\
\hline
\end{tabular}

Table 4: Physical Properties of Coarse aggregates

\begin{tabular}{|c|c|c|}
\hline 1. & Maximum size $(\mathrm{mm})$ & 20 \\
\hline 2. & Specific gravity & 2.62 \\
\hline 3. & Water absorption (\%) & 0.45 \\
\hline
\end{tabular}

Table 5: Fibers specification

\begin{tabular}{|c|c|c|c|c|}
\hline Notation & $\begin{array}{c}\text { Aspect } \\
\text { Ratio }\end{array}$ & $\begin{array}{c}\text { Length } \\
\text { (mm) }\end{array}$ & $\begin{array}{c}\text { Diameter } \\
(\mathbf{m m})\end{array}$ & Shape of fiber \\
\hline SF & 50.0 & 50 & 1.0 & Hooked end \\
\hline
\end{tabular}

\subsection{Casting of Specimens and Testing}

The design mixes of AASC were proportioned based on the volume method. The ratio of coarse: fine aggregate is 1:2.33, with keeping binder ratio $0.4,0.5,0.6$ of alkaline liquid to and sodium silicate to sodium hydroxide ratios for various M1.M2 and M3 AASC mixes. 1 day prior alkaline liquids were prepared with different sodium silicate content. The mixing of all material was done in mixer by addition of fibers by $0 \%, 0.5 \%, 1 \%$ and $1.5 \%$, The homogenous mix of concrete was achieved by workability test. The cube specimens were cast using $100 \mathrm{~mm}$ for determining the compressive strength of concrete mix. Standard cylindrical specimens of $150 \times 300 \mathrm{~mm}$, were cast for tensile strength test. Similarly, beams of 500x100x100 mm prism were used for determining the flexural strength. The specimens were demoulded after $24 \mathrm{hr}$ and cured in ambient temperature. The cured specimens are tested at the age of 3, 7 and 28days respectively.

Compression strength is determined by using Compressive Testing Machine(CTM) of capacity $2000 \mathrm{kN}$ and Flexural strength is conducted by using flexural testing machine by Beams were tested with two point loading applied at $1 / 3 \mathrm{rd}$ span points, so as to obtain pure bending moment region in the intermediate of the beam as shown in fig 4 . Test duration of each beam was about 20 minutes. After failure of the beams photographs of each were taken.

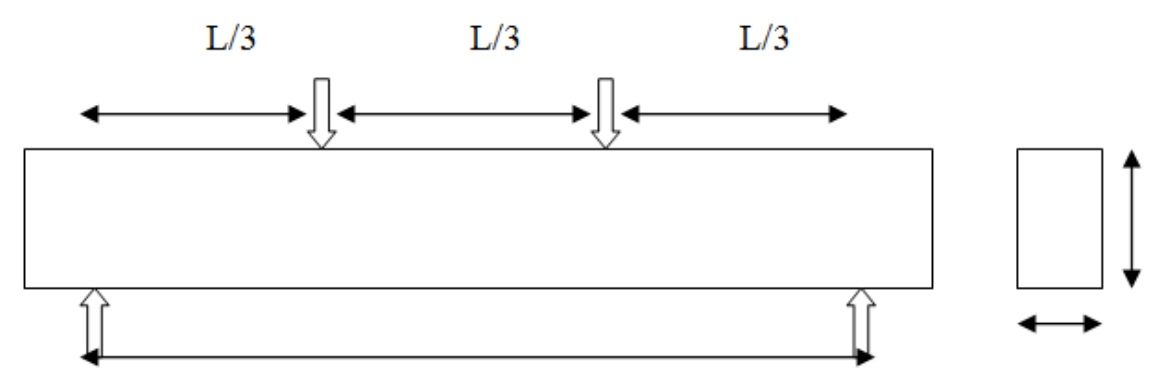

Figure 4 Two point Loading System 


\section{RESULTS AND DISCUSSIONS}

\subsection{Fresh properties of AASC Mixes}

The fresh properties of all AASC Mixes were found to be low as compared to the normal concrete due to the presence of silica \& alumina source as major reaction material in concrete. Workability is assessed by conducting slump test which is decreased with increase in concentrations of $\mathrm{NaOH}$. The figure 5 depicts slump obtained for $\mathrm{M} 3 \mathrm{mix}$ with $4 \mathrm{M}$ was $45 \mathrm{~mm}$ $50 \mathrm{~mm}$ which is more as compared to other AASC mixes.

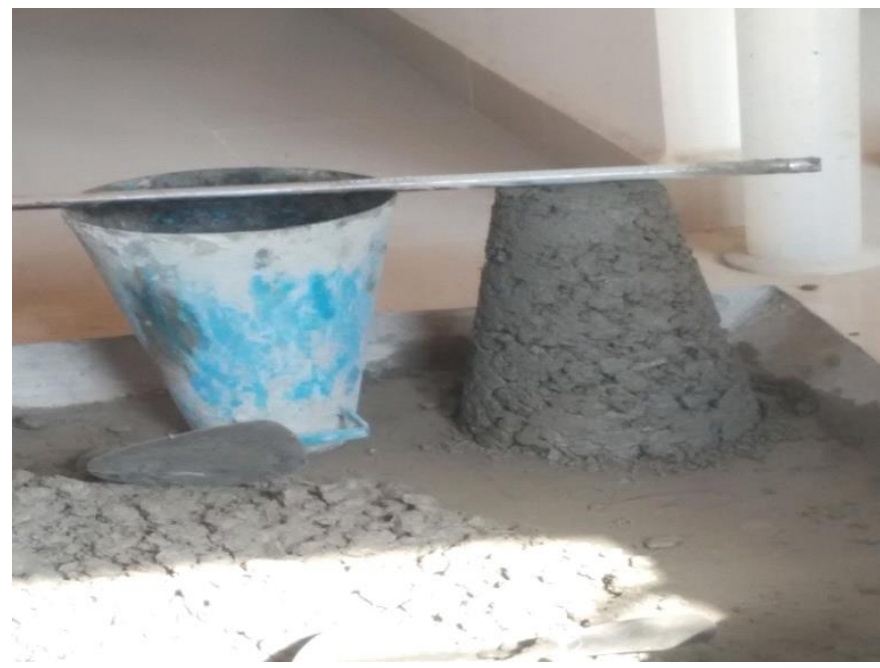

Figure 5 Slump measuring Set up

\subsection{Hardened properties of AASC Mixes}

\subsubsection{Compressive Strength}

The compressive strength of M1, M2 and M3 AASC mixes at the age of 28 days were increased as $\mathrm{Na} 2 \mathrm{SiO} / \mathrm{NaOH}$ ratio increased as depicted in figure 6 to 8 .

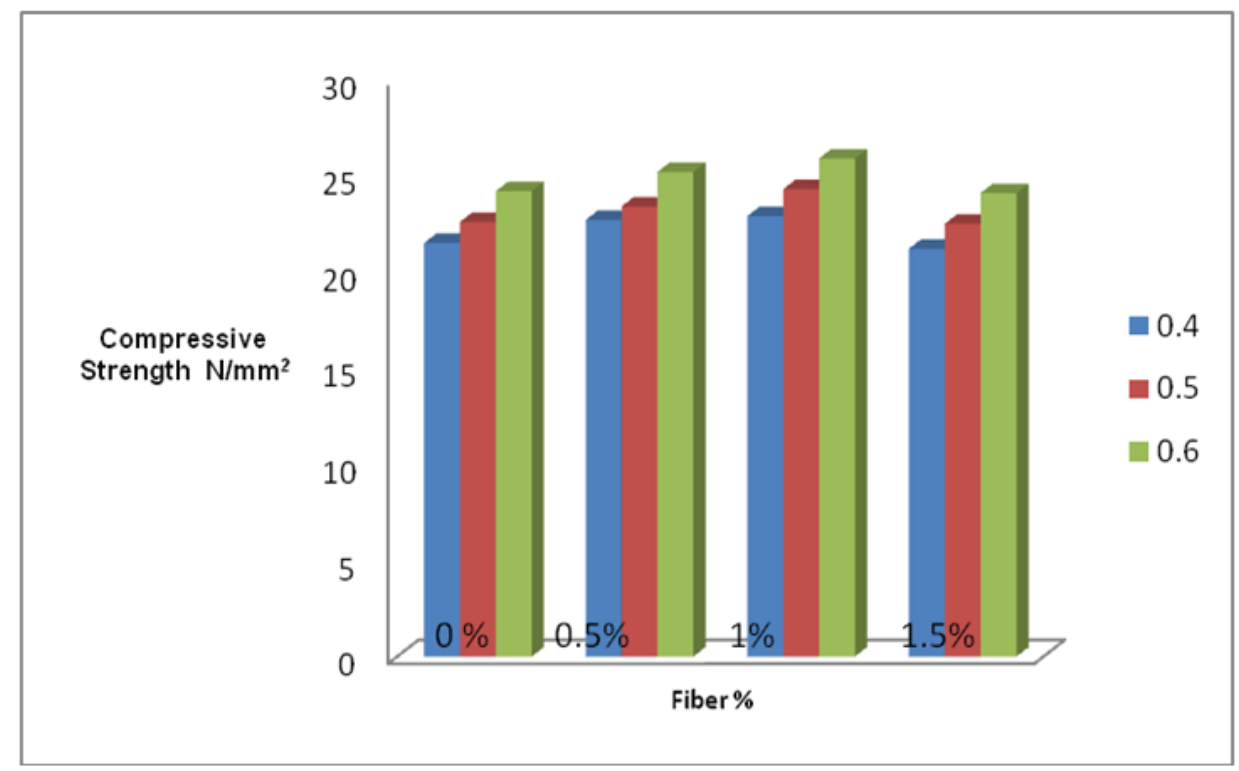

Figure 6 Compressive strength of AASfC Mix -M1 


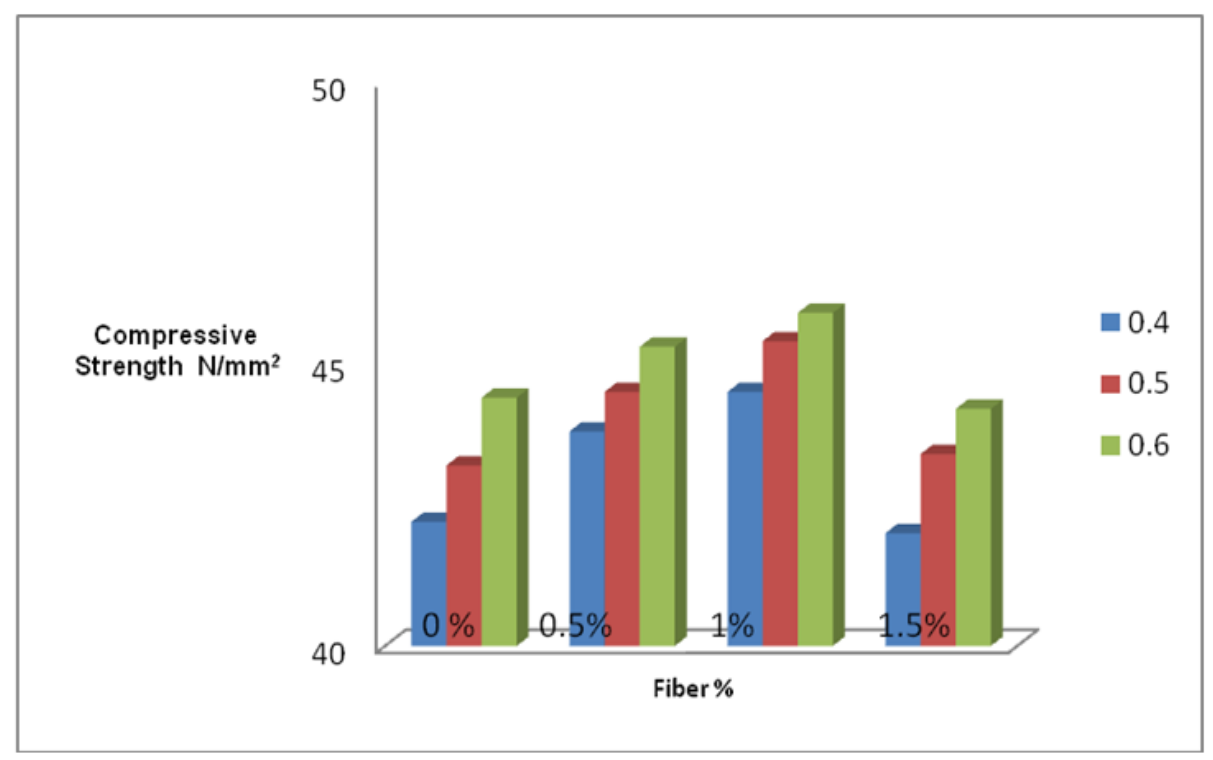

Figure 7 Compressive strength of AASfC Mix -M2

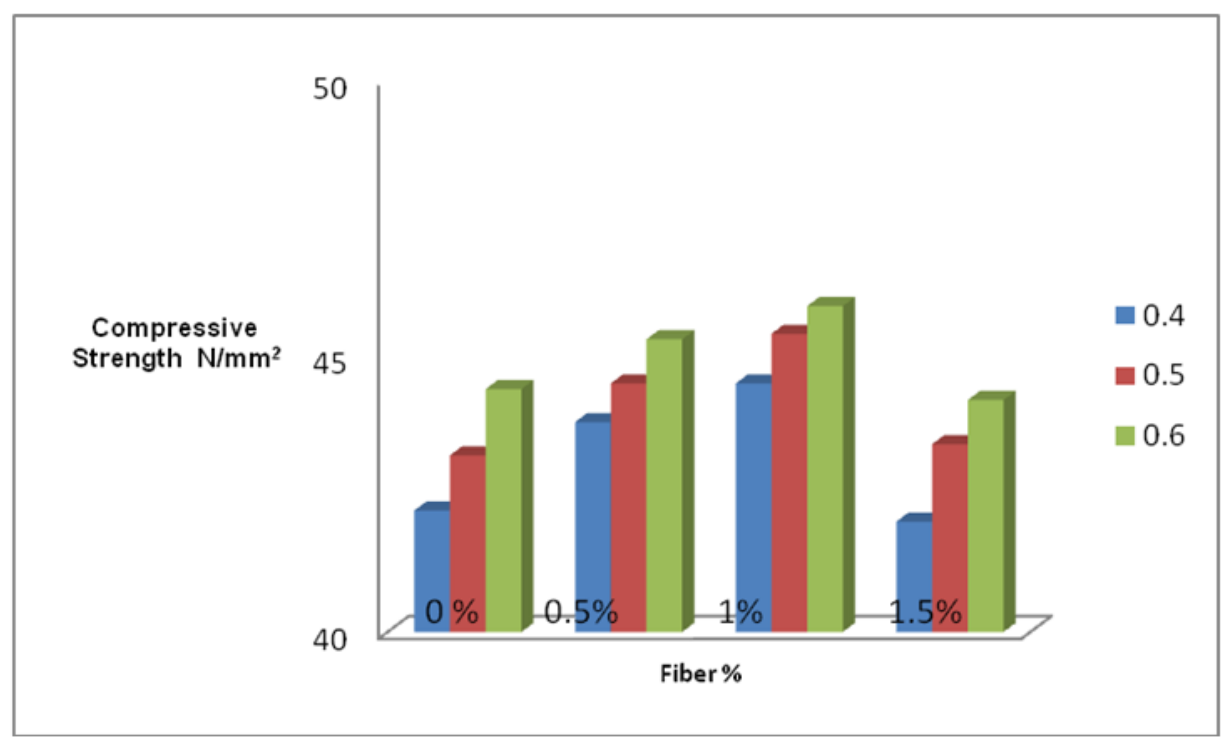

Figure 8 Compressive strength of AASfC Mix -M3

From the figure 6 to 8 it is highlighted that the compressive strength of M3 mixes were increased for 0.5 binder ratio and also notice that better compressive strength is obtained for $1 \%$ fiber content in the mix beyond that percentage of fibre content addition shows decrease in strength as compared to M1 and M2 mixes.

\subsubsection{Split tensile Strength test}

The split tensile strength of M1, M2 and M3 AASC mixes at the age of 28 days were also increased as $\mathrm{Na} 2 \mathrm{SiO} / \mathrm{NaOH}$ ratio increased as depicted in figure 8 to 11 


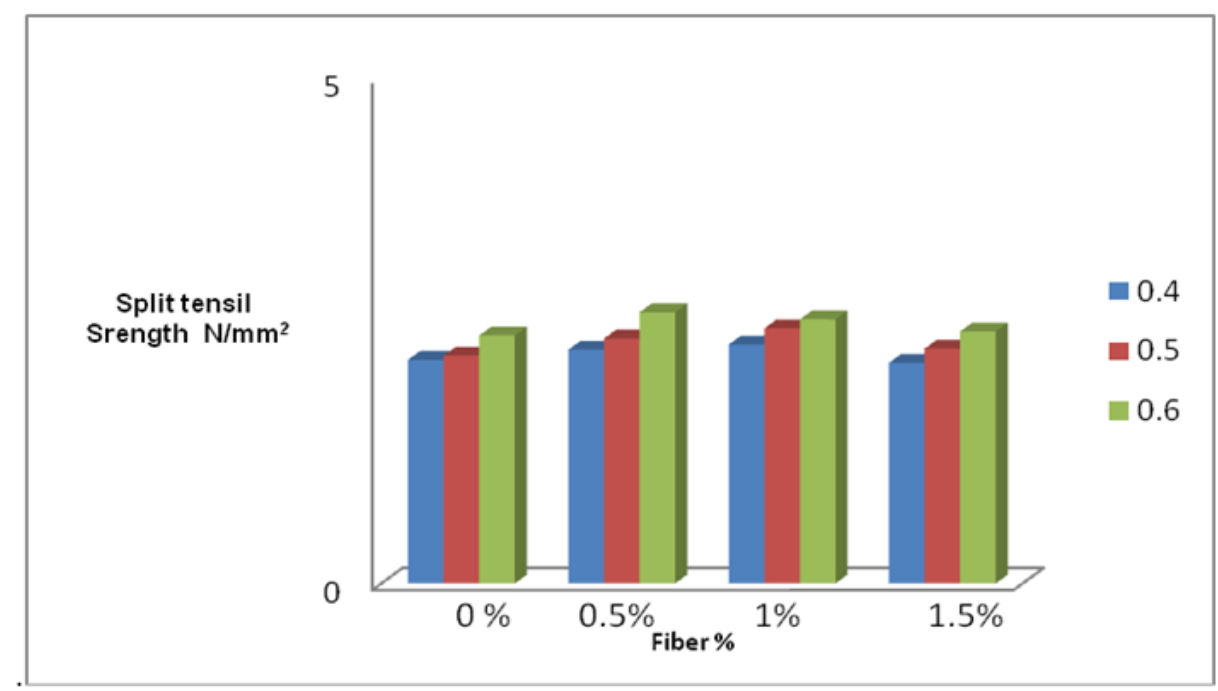

Figure 9 Split tensile strength of AASfC Mix -M1

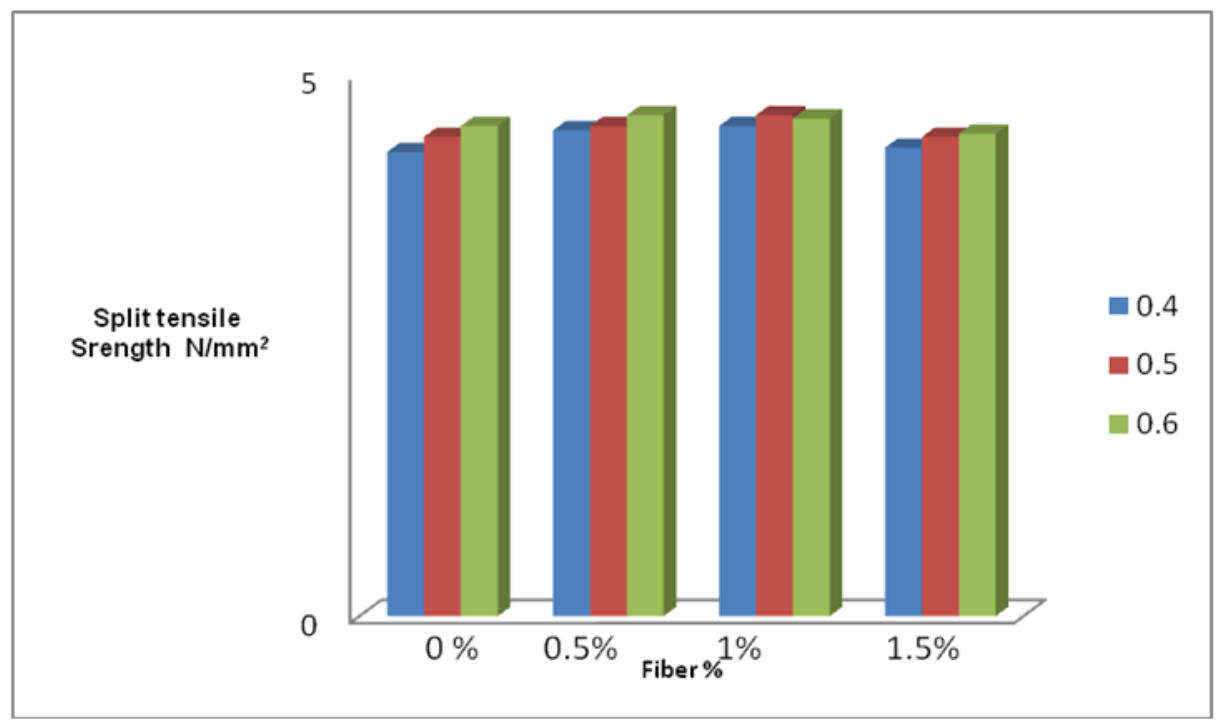

Figure 10 Split tensile strength of AASfC Mix -M2

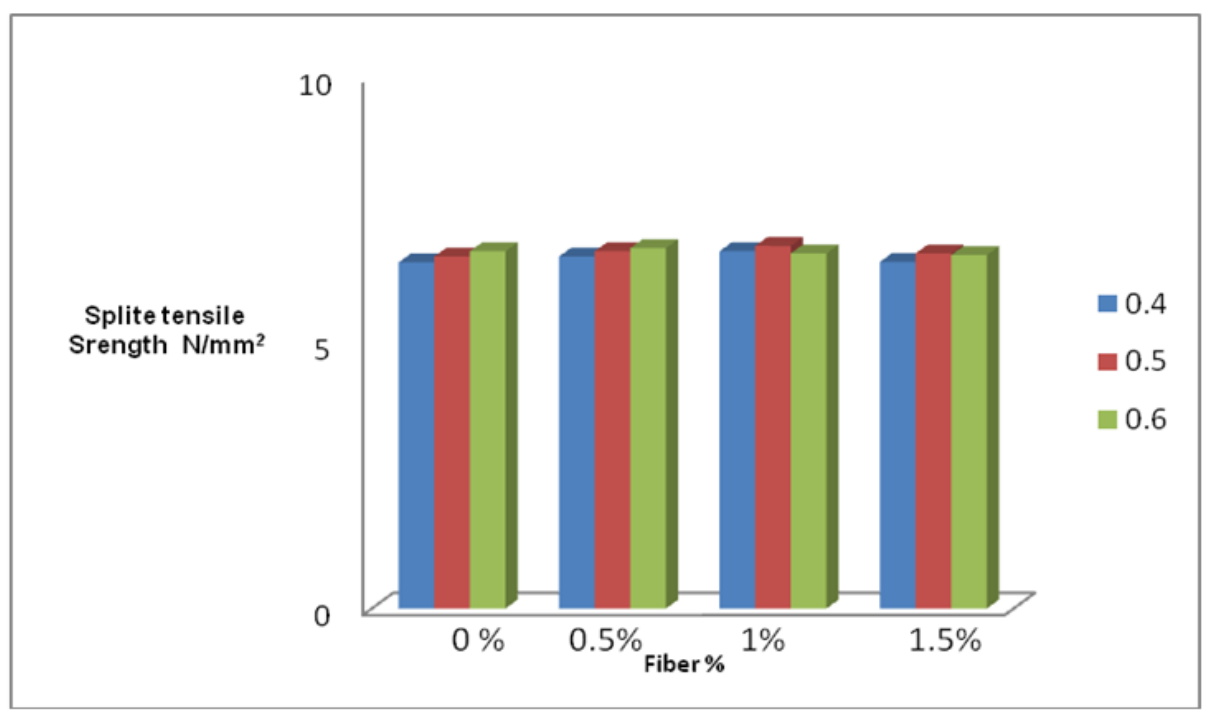

Figure 11: Split tensile strength of AASfC Mix -M3 
From the figure 8 to 11 it is noted that the split tensile strength of M3 mixes were increased for 0.5 binder ratio and also better split tensile strength is obtained for $1 \%$ fiber content in the mix beyond that percentage of fibre content addition shows decrease in strength as compared to $\mathrm{M} 1$ and $\mathrm{M} 2$ mixes.

\subsubsection{Flexural Strength test}

The flexural strength of M1, M2 and M3 AASC mixes at the age of 28 days were also increased as $\mathrm{Na} 2 \mathrm{SiO} 3 / \mathrm{NaOH}$ ratio increased as depicted in figure 11 to 14 .

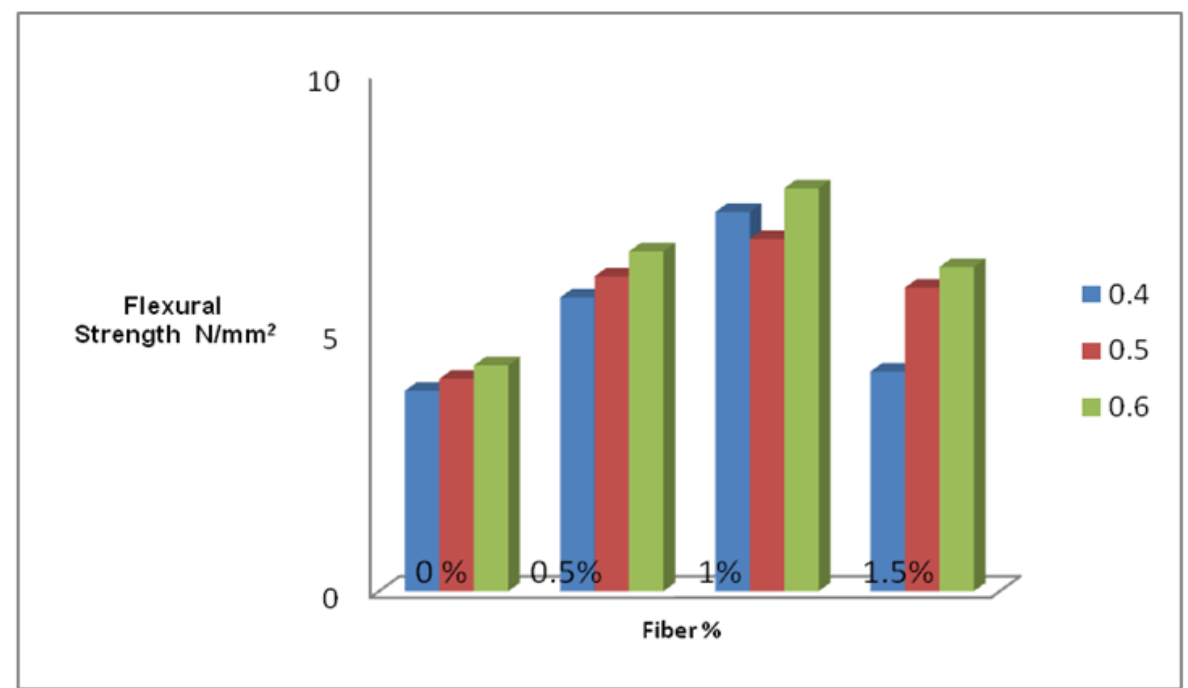

Figure12 Flexural strength of AASfC Mix-M1

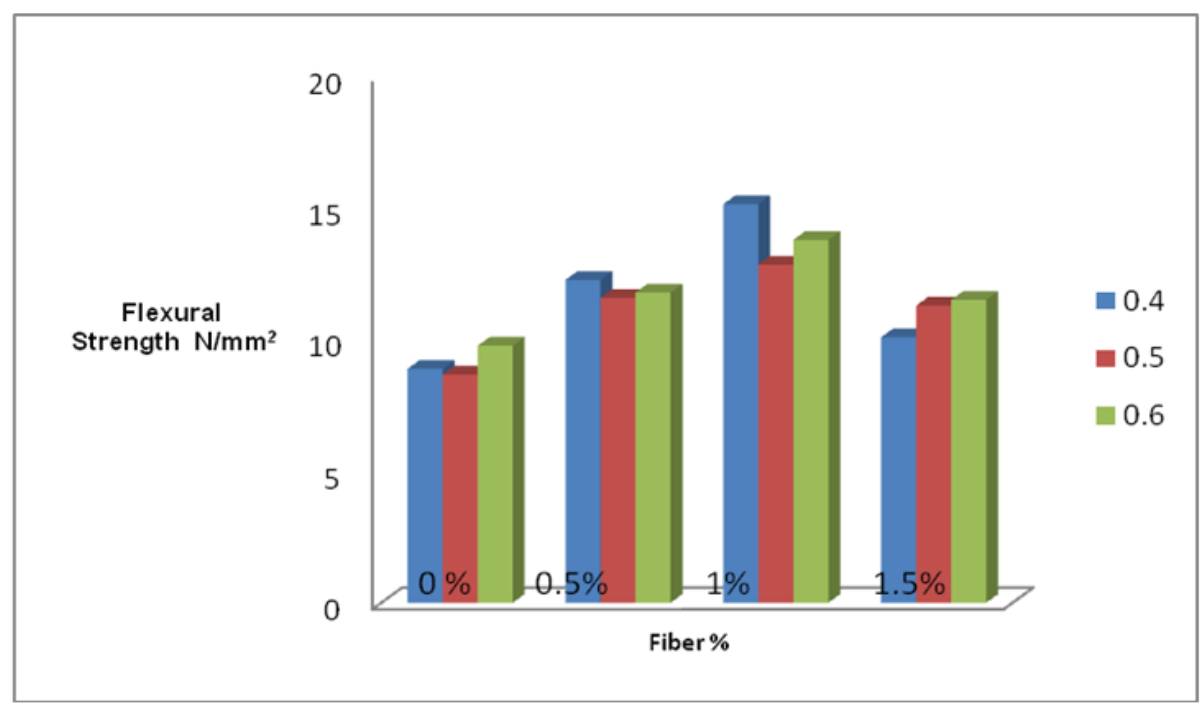

Figure 13 Flexural strength of AASfC Mix-M2

From the figure 11 to 14 it is noted that the flexural strength of M3 mixes were increased for 0.4 binder ratio and better flexural strength is obtained for $1 \%$ fiber content in the mix beyond that percentage of fibre content addition shows decrease in strength as compared to M1 and M2 mixes. This increase in strength is due to the higher concentration of sodium silicate in AASC mixes increased the flexural strength at 28-days and noticed that all the mixes achieved the minimum strength requirement. 


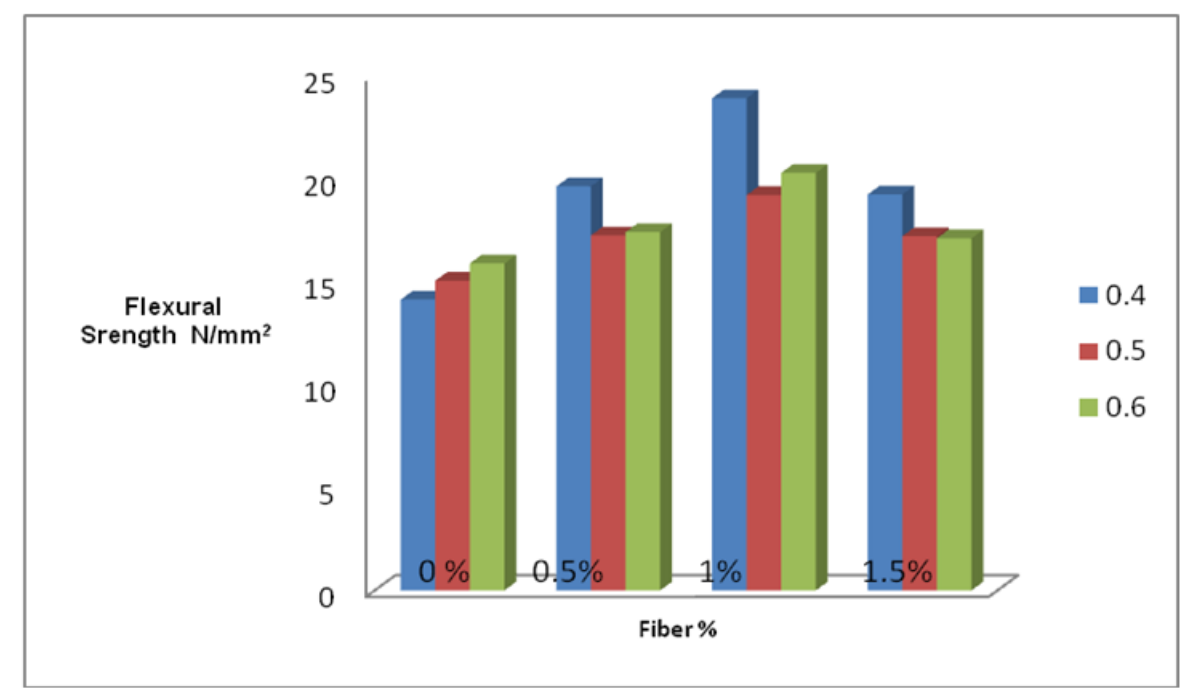

Figure 14 Flexural strength of AASC Mix-M3

\section{CONCLUSION}

The following conclusion can be drawn based on the result obtained in the present study.

- The workability of all alkali activated slag concrete mixes have shown lesser workability than normal concrete.

- The compressive strength and Split Tensile strength of AASC for M2 mix increases with increase in content of sodium silicate for 0.5 binder ratio and $1 \%$ fibre content as compare to other mixes and also the higher convergence of $\mathrm{Na}_{2} \mathrm{SiO}_{3}$ accelerates the geopolymerization response with greater dissolution of the source material.

- The Flexural Strength for M2 mix increases with increase in content of sodium silicate for 0.4 binder ratio and $1 \%$ fibre content as compare to other mixes.

- The alkali activated slag concrete mixes are dense and more compact in fresh and harden states.

\section{REFERENCES}

[1] J.L. Provis, A. Palomo, C. Shi, Advances in understanding alkali-activated materials,Cem. Concr. Res. 78 (2015) 110e125.

[2] V. Bhikshma and T. Naveen Kumar, "Mechanical properties of fly ash based geopolymer concrete with addition of GGBS", The Indian Concrete Journal September 2016.

[3] J.Srinivas and B.Prakash, "An Experimental Study on Effect of Ggbs on strength Characteristicsof Geopolymer Concrete" International Journal of Scientific \& Engineering Research, Volume 7, Issue 7, July-2016, ISSN 2229-5518.

[4] Kannapiran K, Sujatha T and Nagan S. (2013). "Resistance of Reinforced Geopolymer Concrete Beams to Acid and Chloride Migration". Asian Journal of Civil Engineering (Bhrc) Vol. 14, NO. 2 (2013). Pp 225-238.

[5] Wasan I. Khalil and Tayfur Y. R, "Flexural Strength of Fibrous Ultra High Performance Reinforced Concrete Beams", ARPN Journal of Engineering and Applied Sciences, VOL. 8, NO. 3, MARCH 2013 ISSN 1819-6608 
[6] Jyoti Narwal, Ajay Goel, Devender Sharma, D.R. Kapoor and Bhupinder Singh, "An Experimental Investigation on Structural Performance of Steel Fibre Reinforced Concrete Beam”, International Journal of Engineering and Advanced Technology (IJEAT) ISSN: 2249 8958, Volume-2, Issue-6, August 2013.

[7] V. Bhikshma and T. Naveen Kumar, "Mechanical properties of fly ash based geopolymer concrete with addition of GGBS", The Indian Concrete Journal September 2016.

[8] Karthik M. P, Arul Gnanapragasam A, Sree Vidya V, Ragul K,Robert ravi S and Rex J, "Analytical Study on Fibre Reinforced Geopolymer Concrete", International Journal of ChemTech Research, Vol.10 No.8, pp 320-325, 2017, ISSN: 0974-4290,

[9] A. Fern_andez-Jim_enez, F. Puertas, Structure of calcium silicate hydrates formed in alkalineactivated Slag: influence of the type of alkaline activator, J. Am. Ceram. Soc. 86 (2003) $1389 \mathrm{e} 1394$.

[10] Nuruddin M, Sobia Qazi, Shafiq N, Kusbiantoro A. (2011). "Compressive Strength and Interfacial Transition Zone Characteristic of Geopolymer Concrete with Different Cast In-Situ Curing Conditions". World Academy of Science, Engineering and Technology 73 2011.pp 892895.

\section{ABBREVIATION}

GGBS- Ground granulated blast furnace slag

AAS - Alkaline Activator Slag

AASC- Alkaline Activator Slag concrete

M1-Mix one

M2-Mix two

M3- Mix three 